\title{
A CONSTITUIÇÃO DO CORPO DO AUTISTA: DO DESAMPARO À INVENÇÃO
}

\author{
THE CONSTITUTION OF THE AUTIST'S BODY: FROM HELPLESSNESS TO INVENTION \\ LA CONSTITUCIÓN DEL CUERPO DEL AUTISTA: DEL DESAMPARO A LA INVENCIÓN
}

Edivaldo Procópio da Silva*

\begin{abstract}
RESUMO
Este artigo busca a apreensão dos processos envolvidos na constituição do corpo do autista, para o qual não há o Outro de referência. À luz do testemunho de Daniel Tammet, escritor britânico e autista, será possível elucidar o lugar dos objetos para os autistas e como o interesse da pessoa autista pelo objeto fora do corpo permite a construção de sua borda, atuando como recurso protetor contra perturbações corporais, angústias e isolamento. Assim, o investimento nos objetos externos resulta na redução da incidência no corpo do gozo não interligado, abrindo possibilidade para o campo do Outro. Os objetivos pretendidos são examinar o conceito de corpo na psicanálise com relação ao autismo, investigar a constituição do corpo do autista com base na teoria psicanalítica e, por fim, identificar os efeitos, no corpo, do interesse pelos objetos autísticos.
\end{abstract}

Palavras-chave: Autismo. Corpo. Objeto autístico. Psicanálise lacaniana.

\begin{abstract}
This article seeks to apprehend the processes involved in the constitution of the autistic body for which there is not the Other as a reference. In the light of Daniel Tammet's testimony, a British author and autistic writer, it will be possible to elucidate the place of objects for autistic people and how the autistic person's interest in the out-of-body object allows them to build their edge, acting as a protective resource against bodily disturbances, anguish and isolation. Thus, investment in external objects results in a reduction in the incidence on the non-interconnected body of enjoyment, opening the possibility for the field of the Other. The objectives are to examine the concept of body in psychoanalysis in relation to autism, to investigate the constitution of the autistic body from the psychoanalytic theory and, finally, to identify the effects on the body of interest for autistic objects.
\end{abstract}

Keywords: Autism. Autistic object. Body. Lacanian Psychoanalysis.

\footnotetext{
* Especialista em Clínica Psicanalítica na Atualidade: Contribuições de Freud e Lacan, psicólogo, especialista em Abordagem Psicanalítica do Autismo e Suas Conexôes (Instituto de Educação Continuada da Pontifícia Universidade Católica de Minas Gerais - IEC-PUC Minas). Endereço: Rua Oito, 62, ap. 301, bloco 8 - Santa Maria, Contagem-MG, Brasil. CEP: 32240-228. E-mail: edivaldoprocopio@gmail.com.
} 


\section{RESUMEN}

Este artículo busca comprender los procesos involucrados en la constitución del cuerpo autista para el cual no hay otra referencia. A la luz del testimonio de Daniel Tammet, un autor británico y escritor autista, será posible dilucidar el lugar de los objetos para las personas autistas y cómo el interés de la persona autista en el objeto fuera del cuerpo les permite construir su ventaja, actuando como un recurso protector contra las perturbaciones corporales, angustia y aislamiento. Por lo tanto, la inversión en objetos externos muestra como resultado una reducción en la incidencia de goce no conectado en el cuerpo, abriendo la posibilidad para el campo del Otro. Los objetivos son examinar el concepto de cuerpo en el psicoanálisis en relación al autismo, investigar la constitución del cuerpo autista a partir de la teoría psicoanalítica y, finalmente, identificar los efectos, en el cuerpo, del interés por los objetos autísticos.

Palabras clave: Autismo. Cuerpo. Objeto autista. Psicoanálisis lacaniano.

\section{INTRODUÇÃO}

teoria lacaniana define o sujeito como habitante da linguagem em relação ao
significante. Ao ser representado por um significante ao outro significante
$\left(S_{1}-S_{2}\right)$, ele se torna efeito da relação com o Outro. De outro modo, o autista está fora do discurso, com uso muito particular do simbólico e demonstrando, ainda, uma relação sui generis com o corpo.

As pesquisas de Rosine e Robert Lefort (2017) sobre a clínica de sujeitos autistas, a partir da década de 1960, culminaram na proposição do autismo como uma estrutura específica. Com efeito, perguntamos como é a constituição do corpo para esses sujeitos. Este artigo busca a apreensão dos processos envolvidos na constituição do corpo do autista, o qual não há o Outro de referência.

Os ensinamentos de Lacan são adotados, principalmente os pressupostos que fazem uso da lógica e da topologia para a elaboração e embasamento de seus conceitos. Nessa acepção, apreende-se que, sem a incorporação da linguagem, o autista partirá de uma invenção singular para envolver o seu corpo real, dandolhe uma nova conformação e, assim, conseguindo criar um corpo mais articulado com a sua psiquê.

O estudo do testemunho de Daniel Tammet auxiliará na demonstração, por meio deste artigo, de como o interesse do autista pelo objeto fora do corpo permite a construção de sua borda, reduzindo suas perturbações corporais. 
O conceito de corpo é muito caro à psicanálise, em razão de sua importância para os sujeitos. Desde a compreensão freudiana da histeria, enigmas faziam o pai da psicanálise se questionar sobre os sintomas que surgiam no corpo de suas pacientes. As indagações sobre os sintomas, os fenômenos corporais e os acontecimentos de corpo atravessaram gerações de vários psicanalistas e pesquisadores. Foi, no entanto, Jacques Lacan quem estabeleceu a relação do sujeito com o corpo e com a linguagem, abrindo portas para diversas outras elaborações.

Assim, os objetivos pretendidos são examinar o conceito de corpo na psicanálise com relação ao autismo, investigar a constituição do corpo do autista com base na teoria psicanalítica e, por fim, identificar os efeitos no corpo do interesse pelos objetos autísticos. Para tanto, a pesquisa é teórica, baseada em autores psicanalistas afinados com a teoria lacaniana. Teoria e prática serão articuladas por meio da publicação de Tammet a respeito da especificidade e do funcionamento subjetivo singular presente no autismo.

Compreender a constituição do corpo do autista visa, sobretudo, a contribuir para o tratamento desses sujeitos que, frequentemente, encontram-se em situações de graves perturbações capazes de afetar o corpo, a linguagem e a relação com os objetos.

O corpo encapsulado, desenlaçado e sem vida é fonte de sofrimento e também destino para tratar a angústia ante o real. Diante disso, as elucidações a partir da teoria psicanalítica aqui estudada e sua aplicação ao autismo corroboram os estudos e, consequentemente, o tratamento dos sujeitos autistas na clínica.

\section{AUTISMO}

Os autistas apresentam diversas dificuldades, destacando os desafios de coordenação corporal, envolvimento social e na comunicação. A manifestação de tais obstáculos varia consideravelmente entre os autistas. Maleval (2017) aponta que a solidão e a imutabilidade aparecem como os principais sintomas, sendo esses os elementos cruciais para o diagnóstico diferencial.

Existem os autistas que apresentam pouco interesse pelo mundo externo, relacionando à falta de interesse em estabelecer laços sociais. Em alguns casos, eles não têm interesse por grande parte dos objetos que lhes são oferecidos. Com isso a atração desse autista vai em direção ao próprio corpo. Já o corpo fica à mercê de perturbações que expressam o excesso de gozo. Segundo Monteiro (2016), na clínica do autismo, encontra-se uma série de fenômenos de desordem pulsional decorrentes da ausência de montagem do circuito da pulsão e da 
não operação da extração do objeto $a$. As crianças autistas podem apresentar movimentos repetitivos das mãos, balanceios com o corpo e, em situações mais graves, automutilações.

Por outro lado, não é raro algumas crianças criarem um forte vínculo com um objeto escolhido, denominado objeto autístico, designação criada pela psicanalista infantil britânica Frances Tustin (1913-1994). Uma vez eleito, o objeto passa a ter uma importância muito grande para o autista. Para Maleval (2017), "O autista se esforça para desviar do corpo o gozo desvairado e como medida de segurança e defesa se dedica a criação de uma borda através do objeto" (p. 124). Assim, o desinvestimento no corpo ocorre conforme o autista se sente atraído pelo objeto. A matéria passa a ter função de anteparo e de proteção ao Outro invasivo e também contra os efeitos de gozo sobre o corpo do sujeito.

Tammet, um prestigiado autista londrino, ganhou notoriedade mundial após publicar autobiografias. Antes disso, sua infância foi marcada por convulsões epilépticas e pelo comportamento atípico. Em um trecho de seu livro Nascido em um dia azul (Tammet, 2007), ele expõe a gravidade de seu quadro, revelando a desordem pulsional que experimentou. "Aos 2 anos, comecei a andar até certa parede da sala e bater repetidamente com a cabeça nela. Eu balançava o corpo para trás e para frente, batendo a testa com força, repetida e ritmicamente na parede" (p. 26).

O testemunho ilustra bem o uso do corpo como uma tentativa de tratar um gozo mortífero. Logo que começou a fazer uso dos números como seu objeto autístico, ele pôde iniciar gradualmente a construção de uma borda e, assim, desviar o gozo do corpo. Tammet (2007) relata que teve uma infância isolada, mas preenchida com números dotados de cores, formas, texturas e movimentos. Ele dizia que o número 1 parecia-lhe, por exemplo, branco e brilhante, enquanto outros números eram simplesmente tímidos.

$\mathrm{Na}$ infância e na adolescência, o autor contou com o apoio imprescindível dos pais, que respeitavam suas escolhas e eram atentos às particularidades do filho. Quando na vida adulta, a parceria de seu companheiro Niel foi igualmente fundamental. Os pais de Tammet não conseguiam apaziguar o filho após seu nascimento, que não dormia e chorava incessantemente. Nessa ocasião, a família tinha poucos recursos financeiros, e os genitores não sabiam o que ocorria com o bebê, apesar das várias consultas médicas. Um dos métodos encontrados foi deixar Tammet amamentar no peito até os 18 meses seguintes (Tammet, 2007).

A força destrutiva proveniente de uma pulsão de morte e desenlaçada da vida, presente no autismo, se traduz numa grande dificuldade para os pais e para 
os próprios autistas. Esse gozo desmedido aponta para um corpo que não foi constituído, estando tanto o sujeito quanto seu corpo imersos no puro real.

Monteiro (2016) coleta, nos textos freudianos Projeto para uma psicologia científica e Interpretação de sonhos, o desamparo fundamental com o qual todo ser humano se encontra ao nascer. $\mathrm{O}$ sentimento é experimentado pela criança logo ao nascer, que precisa de ajuda alheia para sua sobrevivência, reagindo com choro ou gritos ante o excesso de tensão.

Ao ser acolhido e pela intervenção do Outro, que interpreta e responde ao grito, tomando-o como apelo, o infans experimenta uma sensação de satisfação que ficará inscrita na estrutura como marcas mnêmicas tanto do objeto que proporcionou a satisfação como da imagem do movimento que permitiu a descarga (Monteiro, 2016, p. 65).

A comunicação vivenciada entre o bebê e a sua mãe é de extrema importância para o desenvolvimento emocional do infans. Tomando como base os conceitos construídos por Lacan, Monteiro (2016) explica que a ajuda alheia é comumente exercida pela mãe, referindo-a como lugar do primeiro Outro como o Outro Primordial. Cabe ao Outro Primordial transmitir as demandas e suas faltas, sendo ainda entendido como lugar onde as palavras ganham sentido, do simbólico para $o$ infans.

No ambiente familiar, por sua vez, os pais de autistas observam que seus bebês não se dirigem ao Outro materno. O olhar é perdido no vazio e não há resposta a qualquer chamado, incluindo às cócegas feitas com a finalidade de obter risos. Além disso, nenhuma mensagem corporal é transmitida, e os movimentos corporais são desconexos no espaço. Portanto não ocorre uma relação de troca com o Outro Primordial.

De forma empírica, os pais de Tammet criaram novos métodos para acalmar o filho, gradativamente. Eles demonstraram o quanto é importante a invenção a partir da experiência. Os três primeiros anos de vida de nosso autor foram marcados pelo choro excessivo, várias batidas de mão na cabeça e gritarias incessantes. Por esses motivos, Jennifer e Kevin continuavam balançando Tammet no lençol ou embalando o filho nos braços todos os dias. Ao final desse período, houve uma mudança importante: Tammet passou de um bebê superagitado para uma criança quieta, ensimesmada e indiferente (Tammet, 2007). Em sua escolinha, não tinha nenhum interesse pelas outras crianças.

Destaca-se que, nos três primeiros anos, Tammet passou a dormir sempre com o mesmo brinquedo junto a seu corpo, um coelho vermelho. Isso indica ser seu primeiro objeto autístico. Próximo dessa mesma época, relata que, ao retornar do maternal com seu pai, passando em frente a uma vitrine, chorou de 
forma decidida ao ver um livro que, segundo ele, tinha uma forma amarela e brilhante. $\mathrm{O}$ interesse pelo objeto foi tão intenso que toda a coleção teve de ser comprada nos dias seguintes, ao ele retornar da escola.

Os livros se tornaram companheiros inseparáveis, e Daniel Tammet sentia-se seguro e tranquilo ao ficar horas olhando as cores e as formas das ilustrações. Em alguns momentos, dentro de seu quarto, Tammet arrumava os livros em pilhas no chão até o cercar de todos os lados. Segundo o londrino, os números das páginas proporcionaram-lhe felicidade. Os números e as palavras lhe faziam um contorno, ou seja, ocupavam uma função de borda a seu corpo.

\section{ALGUMAS CONSIDERAÇÕES SOBRE O CORPO PARA A PSICANÁLISE}

O corpo da psicanálise é diferente do corpo biológico. Esse tema ganhou atenção com as elaborações de Lacan, destacando-se as formulações realizadas na década de 1970. Para além da materialidade, precisa-se de várias formaçóes psíquicas para constituir um corpo próprio. Acompanhando nosso autor, a constituição corporal dar-se-á na trama entre o imaginário, o simbólico e o real.

A discussão inicial parte do pressuposto de que, segundo Lacan, o inconsciente é estruturado como uma linguagem. Em O seminário: livro 11 (Lacan, 1985), temos o axioma que um significante é aquilo que representa um sujeito para um outro significante. $\mathrm{O}$ sujeito nasce, então, dessa relação de significantes. Lacan, portanto, deduz, a partir desse desenvolvimento, uma topologia para dar conta da constituição do sujeito e, logo, a incorporação do corpo simbólico.

Para que a constituição do sujeito aconteça, são definidos dois campos: do sujeito e do Outro. De acordo com Lacan (1985), o Outro é "o lugar em que situa a cadeia do significante que comanda tudo que vai poder presentificar do sujeito, é o campo desse vivo onde o sujeito tem que aparecer" (p. 200). Para esse surgimento, ocorrem as operações de alienação e separação.

A alienação é a primeira operação que funda o sujeito. À segunda, tão importante quanto a primeira, Lacan chamou separação. $\mathrm{O}$ sujeito primeiro se aliena no Outro, isto é, no primeiro significante que surge no campo do Outro. Esse significante representará o sujeito para o Outro significante, que então lhe dará um significado ou nomeação, uma vez que esse Outro é o campo onde há o tesouro dos significantes. Caso não ocorra a alienação, o sujeito estará fadado a seu apagamento. 
Podemos localizá-lo em nosso esquema dos mecanismos originais da alienação, esse Vorstellungsrepräsentanz, nesse primeiro acasalamento significante que nos permite conceder que o sujeito aparece primeiro no Outro, no que o primeiro significante, o significante unário, surge no campo do Outro, e no que ele representa o sujeito, para um outro significante, o qual outro significante tem por efeito a afânise do sujeito (Lacan, 1985, p. 213).

De maneira concisa, a segunda operação, denominada separação, é um momento em que o sujeito percebe que há um furo, uma falta tanto de seu lado quanto do Outro. "Uma falta é, pelo sujeito, encontrada no Outro, na intimação mesma que lhe faz o Outro por seus discursos" (Lacan, 1985, p. 209). É nesse momento da apreensão de que algo falta que se dá o início da operação. O fato pode ser observado quando crianças fazem perguntas em busca de respostas aos enigmas que surgem na relação dialética com o Outro.

$\mathrm{Na}$ operação de alienação e separação sobra então um resto. Esse resto é uma falta radical, não simbolizável, a que Lacan chamou de objeto $a$ ou de não senso. Conforme Lacan (2005) nos disse em O seminário 10: a angústia, "O S, sujeito ainda desconhecido, tem que se constituir no Outro e nos quais o $a$ aparece como resto dessa operação" (p. 296). O resto é composto em parte pelo sujeito e em parte pelo Outro.

No início da vida, o ser humano acredita que o seu corpo e o de sua mãe se constituem em um só. E o que se perde dessa relação primordial com a separação é parte do corpo da mãe, tido também como corpo do sujeito. Tal perda é fundamental para que o sujeito entre na cadeia significante. Barroso (2014) ressalta que a não extração do objeto resulta na morte do sujeito, tal como ocorre na psicose. Assim, o sujeito fica alienado e não realiza série na cadeia significante.

Cabe ressaltar que, na psicose, especialmente na esquizofrenia, o corpo é fragmentado. Nesse caso, o sujeito não extrai o objeto $a$, o qual está junto ao corpo do sujeito. É nesse sentido que Barroso (2014) nos explica sobre a extração do objeto $a$, para que, com efeito, o sujeito se posicione no mundo, se expresse e simbolize seu corpo. A operação de queda do objeto ou a não extração do mesmo nos mostra a particular relação do autista com o seu corpo.

A extração do objeto é a condição para que o sujeito tenha acesso à dimensão do Outro, para a incorporação do corpo simbólico e para sua inscrição num discurso. A alienação do sujeito à cadeia significante implica ceder uma parte do corpo, que se torna simbólica de sua relação com o próprio corpo (Barroso, 2014, p. 134).

De acordo com o primeiro ensinamento de Lacan, o corpo está atravessado pela linguagem. Assim, a relação do corpo com a linguagem é intrínseca à 
relação com a pulsão. Nessa direção, a inserção do sujeito no simbólico e a incorporação do corpo envolvem, também, outras importantes conceituações, como a construção teórica sobre a metáfora paterna e o significante do Nome do pai.

Esse significante fálico fará efeito conforme o Outro materno permita a entrada do pai em sua relação com o filho. Em suma, é uma conceituação fundamental, com toda sua implicação ulterior, de forma que permita explicar, por exemplo, a constituição corporal na neurose e psicose, salvaguarda a especificidade de cada estrutura. Em geral, aqui se trata da constituição corporal via simbólico, mas há a outra perspectiva do imaginário.

Ao formular o Estádio do Espelho, por exemplo, Lacan fala de uma construção lógica correspondente à formação do Eu por intermédio da imagem especular. $\mathrm{O}$ Estádio do Espelho é o momento pelo qual a criança vai constituir uma imagem a partir de uma outra que lhe é fornecida. Segundo Barroso (2014), "Trata-se de um momento fundamental de experiência do espelho e paradigmático da constituição do Ideal do eu no espaço do Outro" (p. 159). Mas não somente pelo Estádio do Espelho se constitui um corpo, haja vista que o corpo do autista não foi afetado pelo semelhante. Embora considerando que muito frequentemente o autista dispensa o espelho, Barroso (2014) discute que essa ausência poderá acarretar impasses na constituição das identificações do sujeito.

Por meio do Estádio do Espelho, a criança passa a reconhecer seu corpo, podendo simbolizá-lo e dar-lhe significado a partir da metáfora paterna. No caso da esquizofrenia, a foraclusão do Nome do pai gera a ausência de um ponto de basta, isto é, o corpo fica sem amarração, originando um corpo despedaçado. Já no autismo, apoiando-se nas formulações que o considera uma outra estrutura, o corpo não fragmentará, mas o sujeito se encapsula de modo a operar certa regulação do gozo pulsional.

Como, no autismo, o sujeito tampouco fez a passagem pelo estádio do espelho, ele não constitui a identificação especular, não dispõe, assim, de recursos imaginários: ele opera, então, pela própria via do gozo, uma borda que delimita algo do corpo, produzindo como consequência um efeito de encapsulamento (Padilha \& Lhullier, 2012, p. 127).

No autismo, não é possível falar sobre a constituição do corpo a partir do Estádio do Espelho e muito menos sobre a Metáfora Paterna. Se não há um encontro com o espelho, também não haverá com o outro semelhante. O Outro é eliminado de cena, abolido fortemente pelo autista. Da mesma forma, se não há o encontro com o Outro, não se pode falar em processo de alienação e separação tal como na neurose e psicose. Se não há o Outro, como se constitui o corpo do autista? 


\section{A CONSTITUIÇÃO DO CORPO DO AUTISTA}

O autista encontra-se fora do discurso porque não ocorreu a alienação significante $\left(S_{1}-S_{2}\right)$. Mas ele está na linguagem, um falasser afetado pelo Umsozinho $\left(S_{1}\right)$, depositário da lalangue, isto é, o significante fora da cadeia discursiva. Em consequência, não se opera a castração, que daria ao autista o acesso ao registro do simbólico. Por isso é observado que, no autismo, o sujeito está imerso no real (Padilha \& Lhullier, 2012).

Tammet (2007) disse que somente aos 8 anos de idade conseguiu dominar os cadarços de seus sapatos, já que tinha pouco equilíbrio e coordenação motora. Ele tinha dificuldade em andar de bicicleta e nadar, além disso, nunca dirigiu um automóvel. Absorto, o autista manifesta as dificuldades corporais, não se distancia do que é dele e do Outro. O intervalo que seria gerado no processo de alienação e de separação não ocorreu.

No autismo, a ausência do significante do Nome-do-pai faz com que não haja o ponto capitonê, responsável por assegurar o enlaçamento dos registros. De acordo com Barroso (2014), "A principal função do Nome do pai é promover uma coordenação entre linguagem e gozo de modo a reabilitar o ciframento do gozo pelo significante" (p. 93). Além disso, Barroso (2014) versa que,

Ao contrário da neurose, na psicose, a falta da marca significante no corpo deixa o ser à deriva de uma inscrição no discurso e o corpo desvestido de um semblant. A falha na incorporação do corpo do simbólico se manifesta, sobretudo, na esquizofrenia e no autismo (p. 215).

A não ocorrência do acesso ao simbólico no autismo leva à necessidade de destacar a noção lacaniana de lalíngua. A lalingua está aquém da linguagem e tem uma relação com o Um-corpo, igualmente imerso no real. Ao comentar Lacan, Miller (2009) afirma que, nos casos onde o Outro não existe, o ser humano é qualificado como falasser, ou seja, trata-se da relação da lalíngua com o corpo.

Segundo o autor, a ausência das operações significantes de alienação e separação resulta na falta de efeito no sujeito do significante ou da identificação, conforme analisado com o conceito de metáfora paterna. Para complementar, "Isso tem a ver com o amor, que não é o amor ao pai e sim o amor-próprio, no sentido do amor a Um-corpo" (Miller, 2009, p. 110). Isso não quer dizer que, na relação com o corpo, o autista não possa experimentar a autoestima com relação à sua imagem corporal.

Em seu livro, Tammet (2007) demonstrou como eram difíceis a adaptação com as mínimas tarefas e o convívio com os irmãos. Ele evitava atividades coletivas, 
preferindo aquelas que poderia executar sozinho, como o salto no trampolim e o salto em altura. Ou seja, seu interesse surtia da não interação com o Outro.

Continuando com os exemplos do londrino, Tammet (2007) achava muito difícil ignorar o barulho externo e costumava tapar os ouvidos com os dedos para se concentrar. "O rangido dos dentes sendo escovados era fisicamente doloroso, e depois de passar pelo banheiro, tinha de tapar os ouvidos com as mãos e esperar o barulho passar" (Tammet, 2007, p. 78). Mesmo após escovar os dentes, denota que persistia a reiteração do Um-sozinho, isto é, do significante desenlaçado, reverberando em seu corpo.

O efeito corporal que submete a criança a um horror foi denominado por Laurent de acontecimento de corpo (Padilha \& Lhullier, 2012). É por isso que os barulhos externos eram bloqueados por Tammet, de modo a evitar a incidência da lalíngua no corpo.

De natureza igual, Tammet considerava certos aspectos da língua mais difíceis que outros. Ele afirma: "Considero palavras abstratas bem mais difíceis de entender e tenho uma imagem na cabeça para cada uma que ajuda com que compreenda o sentido" (Tammet, 2007, p. 139). O uso de palavras concretas é uma característica costumeira que revela a busca por uma referência factual.

De acordo com Maleval (2017), a referência ao que existe na realidade está ligada à função da carência do balbucio e da lalíngua. Para outras crianças, o balbucio a princípio não tem sentido, mas logo lhe é ofertado um sentido qualquer, interpretado pelo Outro materno. Ocorre aí uma "cifração do gozo na lalíngua" (Maleval, 2017, p. 105). No autismo, para evitar o Outro da linguagem, a preferência vai em direção da solidão e do mutismo. Trata-se de uma reposta radical com o intuito de proteger, mas revelando-se muito dolorosa para os autistas.

O testemunho de Tammet é abundante quanto às estratégias para escapar da solidão e do tédio. Ao utilizar objetos autísticos, Tammet (2007) pôde encontrar uma forma de estabilizar-se em sua própria existência. "Durante muitos anos, quando criança, acalentei a ideia de criar minha própria língua, como uma forma de aliviar a solidão que costumava sentir de explorar o prazer que as palavras me proporcionavam" (p. 145). Sua maneira de pensar, por meio de signos, cores e cheiros (utilizando referentes factuais), vai ao encontro da explicação de Maleval (2017) sobre os autistas inserirem-se na linguagem por assimilação de signos.

A preferência e referência por signos ocorre em função da falta de organização com os pares de oposiçôes significantes. Tammet (2007) explica que seu cérebro decompóe tudo em elementos concretos e tangíveis. Contudo outros autistas 
se isolam, caindo em solidão desmedida. Quando há uma tentativa de o autista sair da carapaça, começando a fazer uso da linguagem, ainda que seja de modo precário, denota-se que o sujeito cedeu um pouco da carga de gozo que afeta o seu corpo.

Fica desemparado o corpo do autista que, sem passar pelo olhar do Outro, não obteve consistência necessária. Diante do real impossível, Laurent (2014) assegura que, na clínica psicanalítica, a aposta é na invenção, uma "solução particular sob medida" (p. 78) do sujeito autista. As invenções mais notáveis são os objetos autísticos, os interesses específicos e os duplos. Esses mecanismos formam a borda autística, utilizada para proteger o autista do mundo externo caótico, assim como estabelece relações com este mundo e com o próprio corpo.

É um grande desafio para o autista sair de sua posição mortificada, incluindo o silêncio e o ensimesmamento. Os diversos testemunhos desse público têm nos ensinado sobre o modo como cada um cria sua borda autística. Tammet pensava por meio de números, tendo-os, a princípio, como o objeto autístico de maior interesse. Em seguida, elegeu na escrita seu objeto autístico de maior destaque. As publicações de seus livros propiciaram reconhecimento internacional e acesso à vida social, bem como alívio de suas perturbações corporais.

Os relatos de Tammet sobre os seus principais objetos autísticos, isto é, os números, as línguas e a escrita, confidenciam o quão longe ele chegou. Ao recitar milhares de vezes o número PI em um evento beneficente, Tammet se protegia da incidência do significante do Outro em seu corpo. Essa invenção somada à criação de uma nova língua totalmente particular, com palavras cifradas em números, Tammet pôde evoluir dentro do seu autismo, tendo construído uma borda autística efetiva. O resultado é conhecido, abrangendo livros publicados, cessão das estereotipias e estabelecimento de relações interpessoais, inclusive amorosa.

\section{OS EFEITOS NO CORPO DO INTERESSE PELOS OBJETOS}

Os autistas podem manifestar diversas perturbações corporais expressando o excesso de gozo. Aos 4 anos de idade, Tammet sofreu sua primeira crise de epilepsia, que durou uma hora e foi caracterizada como intensa. Apenas após a assistência de uma equipe médica é que ele, aos poucos, retornou ao estado normal. Isso foi possível graças à agilidade do pai, que socorreu o filho, levando-o rapidamente ao hospital e, assim, evitando uma situação que poderia ser mais gravosa. 
Cabe destacar a expressividade com que ocorrem episódios de epilepsia em crianças com autismo. Segundo Pereira, Pegoraro e Cendes (2012), "Aproximadamente $30 \%$ das crianças com autismo desenvolvem crises epilépticas ou alterações eletroencefalográficas" (pp. 92-96). Até então, a neurologia não descobriu se a epilepsia é uma causa ou um sintoma do autismo, permanecendo, ainda hoje, indefinido se as crises epilépticas são causas ou comorbidade. Os autores concluíram que "a convergência de achados e modelos sugere uma sobreposição significativa entre autismo e epilepsia" (Pereira, Pegoraro, \& Cendes, 2012). Entretanto o desafio em identificar o mecanismo de causa-efeito ainda persiste na Contemporaneidade.

Para a epilepsia de Tammet, nenhuma causa aparente foi detectada pelos médicos. Foi ministrado o uso de medicamentos, os quais foram utilizados por três anos seguidos. Após esse período, os anticonvulsivantes foram retirados gradativamente. Tammet (2007) relata que nunca mais teve crises, inclusive seu desempenho na escola melhorara sem o uso dos remédios.

Nessa circunstância, Tammet (2007) afirma que a epilepsia lhe deixou marcas desde a vivência da forte convulsão. Ele a descreve como uma experiência de queda involuntária, sendo que a epilepsia pode ter desempenhado um papel importante em fazer dele a pessoa que é hoje. Tammet cita outros autores que tiveram a mesma experiência com a epilepsia. Menciona que o escritor russo Fiódor Dostoiévski criou personagens epiléticos em quatro romances, em virtude de sua experiência com a doença. Também acredita que o escritor Lewis Carrol descreveu, no romance Alice no País das Maravilhas, a mesma experiência de queda involuntária que sentira, bem semelhante à de um ataque epilético.

Desde muito cedo, os pais de Tammet perceberam sua obsessão pelos números e não só a toleravam como também incentivavam o filho. Um exemplo era a brincadeira com as castanhas, que ele colhia no jardim e as contava várias vezes. Certa vez, a mãe comprou um livro de enigmas matemáticos para crianças, devorado durante horas por Tammet, que elaborava padrões para resolver as questôes. Os números formavam padrões visuais em sua mente, que o tranquilizavam e viravam seus amigos (Tammet, 2007).

Além dos números, as línguas figuravam entre os objetos autísticos eleitos por Tammet. Ele dominava 11 idiomas: inglês, francês, finlandês, alemão, espanhol, lituano, romeno, estoniano, islandês, galês e esperanto. Os números e as línguas fazem borda ao corpo de Tammet. Conforme ele constrói seu interesse específico, contornando seu corpo, outras habilidades são adquiridas. 
Somente ao me aproximar da puberdade por fim subitamente perdi o medo de estar na água e descobri que consegui flutuar e me mover sozinho, sem as boias de braço. A sensação de euforia foi imensa e parecia que eu tinha dado um enorme passo à frente. Meu corpo finalmente começa a fazer as coisas que eu queria (Tammet, 2007, p. 80).

Ao construir sua borda, o sujeito autista revela suas principais particularidades. Tal invenção expressa sua singularidade e lhe proporciona sustentação no mundo, bem como consistência ao corpo. Segundo Laurent (2014), "As diferentes construções produzidas pelas crianças autistas nos indicam a função de um órgão suplementar que a criança tenta extrair ou introduzir como o órgão que conviria à linguagem no seu corpo" (p. 52).

A inserção de Tammet no convívio social foi permeada por dificuldades, mas suas habilidades numéricas e linguísticas o ajudaram. Ir ao clube toda semana para jogar xadrez com outros jogadores, aos 11 anos, demonstra uma de suas técnicas para superar as barreiras de interação social.

Alguns sintomas corporais só se manifestaram durante um período específico da infância, como a incapacidade para manter contato visual, comportamento repetitivo e estereotipado, agitação e autoagressão. O início da juventude, marcado por dúvidas em relação ao ensino superior, fez com que Tammet viajasse para outro país a fim de fazer trabalho voluntário, ensinando inglês. Foi um grande passo em sua vida.

Os objetos autísticos têm efeitos na função de separação do corpo e do gozo invasivo. Os objetos autísticos compóem a borda corporal com o duplo e o Outro de síntese, em defesa contra a angústia que devasta o sujeito. Nesse sentido, os objetos autísticos são imprescindíveis na regulação do gozo desvairado e para abrir caminhos levando a pessoa com autismo a desfrutar de independência, estabelecer contatos sociais, amorosos e seguir uma carreira profissional.

\section{CONSIDERAÇÕES FINAIS}

A análise dos testemunhos extraídos do livro de Daniel Tammet permite concluir que a construção do objeto autístico e o seu uso na defesa autística possibilitou a constituição de seu corpo. A infância do autor foi extremamente conturbada com movimentos repetitivos, automutilações, ataques de cólera, crises constantes e falta de coordenação motora. Com muito esforço e investimento nos objetos externos ao corpo, construiu sua borda, resultando na redução da incidência no corpo desse gozo não interligado. Entendemos que, ao dedicar à criação da borda, conforme aponta Maleval (2017), Tammet pôde separar seu mundo controlado do mundo caótico externo. 
Tammet (2007) afirmou a relevância de seu engajamento na escrita. Somente após debruçar-se na escrita, para que o mundo conhecesse sua história, ele pôde enxergar um horizonte, repleto de autorrealização e sentido. Os pais tiveram um papel crucial nessa trajetória, com a sagacidade para a especificidade do filho, respeitando sua forma de ser e permitindo seu envolvimento insistente com alguns objetos. Mas foi sobretudo um intenso trabalho de Tammet na construção de seus objetos e de sua borda para ser o que é atualmente: um escritor famoso e com outras tantas realizaçôes que o permitem viver no mundo real.

Nesse sentido, sustentamos a importância dos objetos para os autistas. Para Maleval (2017), a função do objeto consiste em tratar o gozo que retorna na borda. O psicanalista também afirma que os objetos são captadores de libido, reguladores de gozo. Contudo a autobiografia de Tammet demonstra a investidura nos livros e, na escrita, culminou na diminuição do desamparo. Os objetos permitiram o investimento que não fosse somente ao corpo, abrindo possibilidade para o campo do Outro.

As diferentes autobiografias de autistas com alto desempenho têm evidenciado como cada um utiliza seus próprios objetos autísticos para tratar o corpo sem lei e como essa relação vai compor a sua borda autística. Segundo Grandin (1999), sua invenção foi a máquina do abraço, de maneira que esse objeto lhe pressionava dando um contorno em seu corpo. Já Williams (2012) teve os duplos como invenção, enquanto Higashida (2014), a escrita. A libido de cada um foi condensada a partir de seus objetos autísticos, portanto eles atuam como fonte do desenvolvimento para o alívio ao mal estar corporal.

O lugar dos objetos para o autista pode ser essencial na operação de constituição do corpo, em uma nova forma que refreia o gozo e protege da angústia, e possibilitando ainda que a pulsão contorne um objeto fora do corpo. As experiências de Tammet, elucidadas em sua obra, evidenciam estratégias que devem ser adotadas clinicamente, oportunizando uma produção positiva e estabilizante. Nesse sentido, a psicanálise contraindica a retirada dos objetos de pessoas com autismo. A retirada forçada desses desampara o sujeito de sua invenção, construída arduamente para mediar o seu mundo com o do Outro. 


\section{REFERÊNCIAS}

Barroso, S. F. (2014). As psicoses na infância: o corpo sem a ajuda de um discurso estabelecido. Belo Horizonte: Scriptum.

Grandin, T. (1999). Uma menina estranha: autobiografia de uma autista. São Paulo: Cia. das Letras.

Higashida, N. (2014). O que me faz pular. Rio de Janeiro: Intrínseca.

Lacan, J. (1985). O seminário: livro 11: os quatro conceitos fundamentais da psicanálise. Rio de Janeiro: Jorge Zahar.

Lacan, J. (2005). O seminário: livro 10: a angústia. Rio de Janeiro: Jorge Zahar.

Laurent, É. (2014). A batalha do autismo: da clínica à política. Rio de Janeiro: Jorge Zahar.

Lefort, R., \& Lefort, R. (2017). A distinção do autismo. Belo Horizonte: Relicário.

Maleval, J.-C. (2017). O autista e a sua voz. São Paulo: Blucher.

Miller, J.-A. (2009). Perspectivas do seminário 23 de Lacan: o sinthoma. Rio de Janeiro: Jorge Zahar.

Monteiro, K. (2016). O autista e seus objetos. Rio de Janeiro: 7 Letras.

Padilha, R., \& Lhullier, L. (2012). Autismo: uma leitura para além dos limites do simbólico. In A. Murta, A. Calmon, \& M. Rosa (Orgs.), Autismo(s) e atualidades: uma leitura lacaniana. (pp. 117-134). Belo Horizonte: Scriptum.

Pereira, A., Pegoraro, L. F. L., \& Cendes, F. (2012). Autismo $\mathrm{e}$ epilepsia: modelos e mecanismos. Journal of Epilepsy and Clinical Neurophysiology, 18(3), 92-96. Recuperado a partir de http://www.scielo.br/scielo.php?script=sci_arttext\&pid=S1676$26492012000300005 \& \operatorname{lng}=$ en $\& n r m=$ iso

Tammet, D. (2007). Nascido em um dia azul: por dentro da mente de um autista extraordinário. Rio de Janeiro: Intrínseca.

Williams, D. (2012). Meu mundo misterioso: testemunho excepcional de uma jovem autista. Brasília: Thesaurus. 